\title{
Nano education with interactive visualization
}

\author{
Konrad Schönborn, Gunnar Höst and Karljohan Lundin Palmerius
}

\section{Linköping University Post Print}

N.B.: When citing this work, cite the original article.

Original Publication:

Konrad Schönborn, Gunnar Höst and Karljohan Lundin Palmerius, Nano education with interactive visualization, 2016, Nano Today

http://dx.doi.org/10.1016/j.nantod.2015.10.006

Copyright: Elsevier http://www.elsevier.com/

Postprint available at: Linköping University Electronic Press

http://urn.kb.se/resolve?urn=urn:nbn:se:liu:diva-130483

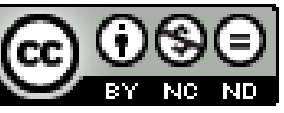




\section{Nano education with interactive visualization}

\section{Keywords}

Nano education; Public understanding; Science education; Nano literacy; Interactive visualization; Virtual reality

\section{Summary}

Future societal and economic impacts of nanoscience and nanotechnology raise the demand for a nano-literate public as well as a nano-competent workforce. This translates into the urgent need for nano education interventions in schools and informal learning contexts. In seeking to meet this mandate, we have developed and investigated a virtual reality environment that induces immersive presence (feeling as being 'in' the virtual world) and exploits bodily movements (e.g. hand gestures to control virtual objects) for students and citizens to learn nano concepts. In this article, we argue that such scientifically-informed immersive and interactive visualizations have a unique potential in communicating nanoscale ideas to students as well as the general public.

\section{Introduction}

The revolutionary progress of nanoscience presents wide-ranging and significant societal and teaching challenges. This requires education initiatives that encompass the convergence between physical, life and engineering sciences that result from scientific endeavour at the nanoscale [1,2]. Thus, future education in both formal (e.g. schools) and informal (e.g. science centres) settings must be equipped with the necessary tools to provide and communicate nano-related knowledge [3]. While rising to this challenge, nano also inadvertently serves as a catalyst [4] for fostering interest 
and motivation in science and technology at large [5].

\section{A pressing need for a public understanding of nano}

The advent of innovative nanomaterials and pioneering nanotherapies marks the growing influence of nano in our daily lives [6]. As part of this swift development, the public will play an important role in interpreting the implications of nano in society $($ e.g. $[3,7,8])$. Public citizens need knowledge that they can deploy as a barometer with which to make scientific judgements about the perceived hopes and fears of nano [7,9-11]. Cultivating such a "nano literacy" [12] requires the development of nanoscience skills and taking cognisance of nano-related societal issues. However, current research suggests that the public has limited awareness and knowledge about nano (e.g. $[9,10,13-$ 15]). Therefore, further careful development and implementation of nano education interventions is necessary to advance public engagement (e.g. [12,16-19]).

\section{A pressing need to integrate nano in traditional school science subjects}

Meeting the future need for a nano-skilled workforce also requires students to be exposed to nano concepts in school. This calls for the integration of nanoscience and nanotechnology into school science teaching (e.g. [1,20]). As part of one such educational initiative, Stevens et al. [21] have unpacked nine 'big ideas' of nano for the school level, that comprise Size and scale, Structure of matter, Forces and interactions, Self-assembly, Quantum effects, Size-dependent properties, Tools and instrumentation, Models and simulations, and Science, technology, and society. In line with the convergent nature of nano, such conceptual building blocks underpin nano-related understanding and at the same time offer cross-disciplinary links to scientific knowledge at large. By the same token, nano has been heralded as a powerful point of departure to teach science content that is otherwise by tradition divided into the separate school subjects of physics, chemistry, and biology (e.g. [22]). However, it remains cognitively demanding for learners to comprehend nanoscopic structures and processes. Examples of documented challenges for learners, some of which our own work has also confirmed (e.g. [11]), include interpreting the relative size of the nanoscale [20], 
invalid anthropomorphic reasoning [23,24], and grasping the counterintuitive notion that emergent properties can arise from random interactions [20,25].

\section{Accessing nano with immersive and interactive visualization in formal and informal settings}

One potential approach to learning and teaching nano lies in exploiting immersive and interactive visualization technology as an educational opportunity (e.g. [20,26,27]). The theory of embodied cognition suggests that human learning is based primarily on our bodily experiences in the world [28]. Accordingly, our sensorimotor experiences have a significant cognitive influence on the way we develop scientific knowledge as individuals (e.g. [29]). Moreover, interactive digital environments that induce a sense of virtual presence can enhance engagement with, and learning of science [27]. However, few such environments have been developed for nano education purposes. For instance, Jones et al. (e.g. [30]) have found that high school students' exploration of AFM data through multiple human senses (e.g. vision and touch) influences their understanding of the morphology and dimensionality of viruses, and fosters an immersive and engaging learning experience.

In our own work, we have tested the hypothesis that immersive virtual reality environments wherein learners use bodily movements to actively interact with virtual nano-objects could grant access to otherwise imperceptible nano-related concepts. Our research programme has involved development of an immersive and interactive virtual reality system, and empirical investigations of science center visitors' and high school students' interaction with the visualization in learning about nano. The visualization incorporates scenarios across a risk (e.g. nano-toxicity) - benefit (e.g. nanotherapy) continuum. During interaction, users have the opportunity to learn core nanoscience concepts (e.g. adhesive 'sticky'forces predominate at the nanoscale, and nanotubes can be designed to bind to specific target cells inside the body, also see [11]), which then forms the basis for users to negotiate their perceived fears and hopes of nano (e.g. 'It's both good and bad. It depends on how you look at it' (student quote from [31])). Figure 1 represents examples of design and interactive features of the visualization related to the nano-therapy scenario. 
[Location of Figure 1 is about here]

Figure 1 An immersive and interactive visualization environment for granting access to a simulated nanoworld. In this example, the virtual environment communicates principles behind targeted drugdelivery. A) A functionalized nanotube modelled in the simulation. B) A user interacts with functionalized nanotubes (visualized in grey with attached molecules in yellow) in the vicinity of a cancer cell membrane that expresses specific receptors (also in yellow). C) A microscopic image integrated in the system showing functionalized nanotubes (red) bound to the cancer cell membrane (cell nucleus in blue), where the bar represents $10 \mu \mathrm{m}$ (image from [32]).

As shown in Figure 1, we modelled a molecular construct that consisted of a short nanotube functionalized with ligand molecules that have affinity for cancer cell receptors (see Fig $1 \mathrm{~A}$ ). The 3D visualization simulates nanoscale intermolecular dynamics such as adhesive forces between surfaces, Brownian motion of molecules in solution and a directional flow of tissue fluid. A learner can reach into the 3D virtual space and deploy 'grab' hand gestures by making contact between forefinger and thumb on each hand to make contact with the functionalized virtual nanotubes (see Fig 1 B). The grab gesture is represented on the display by green circles while an orange line indicates successful contact with a nanotube. By clasping, moving, pulling, pushing and releasing the nanotubes at will near the cancer cell surface (Fig $1 \mathrm{~B}$ ), the learner explores the nanoscale level interactions and dynamics that underlie the nano-therapy scenario. Doing so allows users to map their experiences to the manifestation of nanoscale events (in this case translating into a 'benefit' example of nano) at higher levels of biological organisation (see Fig 1 C). Subsequent photothermal tumour destruction is also communicated by the interactive visualization but not shown here.

Results from our studies indicate that interacting with the system induces a sense of presence in the virtual world, which may increase engagement with the communicated content [31]. In addition, 
findings from analysis of students' real-time verbal descriptions of their experiences while interacting with the system indicate that the gesture-based interaction is often perceived as if users were in actual physical contact with the virtual objects [31]. Such experiences could aid in gaining the nano-related understanding that, for instance, intermolecular forces determine the binding of modified nanotubes to cell surface receptors and that nanotubes do not "seek out" their targets. Current analysis of an experiment where users responded to a nano knowledge test (that we developed and validated, see [11]) before and after interacting with the system, further indicates that the visualization improves citizens' knowledge of nano.

\section{Future of nano in education and the role of immersive and interactive visualization}

The accelerating impact of nanotechnology on society suggests an urgent need to develop the nano education agenda. Citizens need to be able to make informed democratic decisions about emerging technologies, and therefore, nano knowledge will be an important pillar of future scientific literacy [12]. At the same time, equipping a future workforce with relevant nano skills requires school curricular reform that reflects and integrates cross-disciplinary science subject connections derived from a nano context (e.g. [1,20,33]). Scientifically-based immersive visualization is one tool for meeting these objectives that allows learners and citizens to access the nanoworld and integrate their interactive experiences into the learning of otherwise abstract nanoscience concepts. Hence, we suggest that future development and testing of visualizations for accessing nano concepts will play a pivotal role in meeting the demands that the nano revolution places on informal and formal nano education.

\section{Acknowledgements}

The Swedish Research Council (Vetenskapsrådet, grant 2011-5569) supported this work. The authors thank colleagues at Linköping University for valuable discussions. 


\section{References}

[1] M.C. Roco, Medicine, Curr. Opin. Biotech. 14 (2003) 337-346.

[2] G.M. Whitesides, Small 1 (2005) 172-179.

[3] J.K. Gilbert, H.-S. Lin, Int. J. Sci. Educ. Part B. 3 (2013) 267-292.

[4] N. Healy, J. Nano Educ. 1 (2009) 6-7.

[5] R.P.H. Chang, Nano Today 1 (2006) 6-7.

[6] C. Sealy, Nano Today 1 (2006) 1.

[7] M.C. Roco, W.S. Bainbridge, J. Nanopart. Res. 7 (2005) 1-13.

[8] R.V. Burri, S. Bellucci, J. Nanopart. Res. 10 (2008) 387-391.

[9] A.M. Waldron, Nano Today 1 (2006) 56.

[10] H. Schütz, P.M. Wiedemann, Public Underst. Sci. 17 (2008) 369-379.

[11] K.J. Schönborn, G.E. Höst, K.L. Palmerius, Chem. Educ. Res. Pract. 16 (2015) 346-354.

[12] A. Laherto, Sci. Educ. Int. 21 (2010) 160-175.

[13] C.-J. Lee, D.A. Scheufele, B.V. Lewenstein, Sci. Commun. 27 (2005) 240-267.

[14] M.A. Dyehouse, H.A. Diefes-Dux, D.E. Bennett, P.K. Imbrie, J. Sci. Educ. Technol. 17 (2008) 500-510.

[15] S.-F. Lin, H.-S. Lin, Y.-Y. Wu, J. Sci. Educ. Technol. 22 (2013) 548-559.

[16] W.S. Bainbridge, J. Nanopart. Res. 4 (2002) 561-570.

[17] M.D. Cobb, J. Macoubrie, J. Nanopart. Res. 6 (2004) 395-405.

[18] M. Siegrist, C. Keller, H. Kastenholz, S. Frey, A. Weik, Risk Anal. 27 (2007) 59-69.

[19] I. Marschalek, M. Hofer, K. Handler, Nanotechnologies: A Subject for Public Debate, Vienna, Austria, NP 290575, 2014.

[20] M.G. Jones, R. Blonder, G.E. Gardner, V. Albe, M. Falvo, J. Chevrier, Int. J. Sci. Educ. 35 (2013) 1490-1512.

[21] S. Stevens, L. Sutherland, J.S. Krajcik, The Big Ideas of Nanoscale Science \& Engineering: A guidebook for Secondary Teachers, NSTA Press, Arlington, VA, 2009.

[22] M. Orgill, S.A. Wood, J. Nano Educ. 6 (2014), 83-108.

[23] M.W. Klymkowsky, K. Garvin-Doxas, PLOS Biol. 6 (2008) e3.

[24] S. Loeve, B.B. Vincent, F. Gazeau, Nano Today 8 (2013) 560-565.

[25] G.E. Höst, C. Larsson, A. Olson, L.A.E. Tibell, CBE-Life Sci. Educ. 12 (2013) 471-482.

[26] D.S. Goodsell, Nano Today 1 (2006), 44-49.

[27] C. Dede, Science, 323 (2009), 66-69.

[28] M. Wilson, Psychon. B. Rev. 9 (2002), 625-636.

[29] T.G. Amin, F. Jeppsson, J. Haglund, Int. J. Sci. Educ. 37 (2015) 745-758.

[30] M.G. Jones, T. Andre, R. Superfine, R. Taylor, J. Res. Sci. Teach, 40 (2003) 303-322.K.J.

[31] Schönborn, G.E. Höst, K.L. Palmerius, J. Flint, Int. J. Virt. Pers. Learn. Environ. 5 (2014) 4056.

[32] Y. Xiao, X. Gao, O. Taratula, S. Treado, A. Urbas, R.D. Holbrook, et al., BMC Cancer 9 (2009) 1-11.

[33] G.E. Höst, K.J. Schönborn, K.E. Lundin Palmerius, Educ. Res. Int. 2013 (2013), 1-11. 

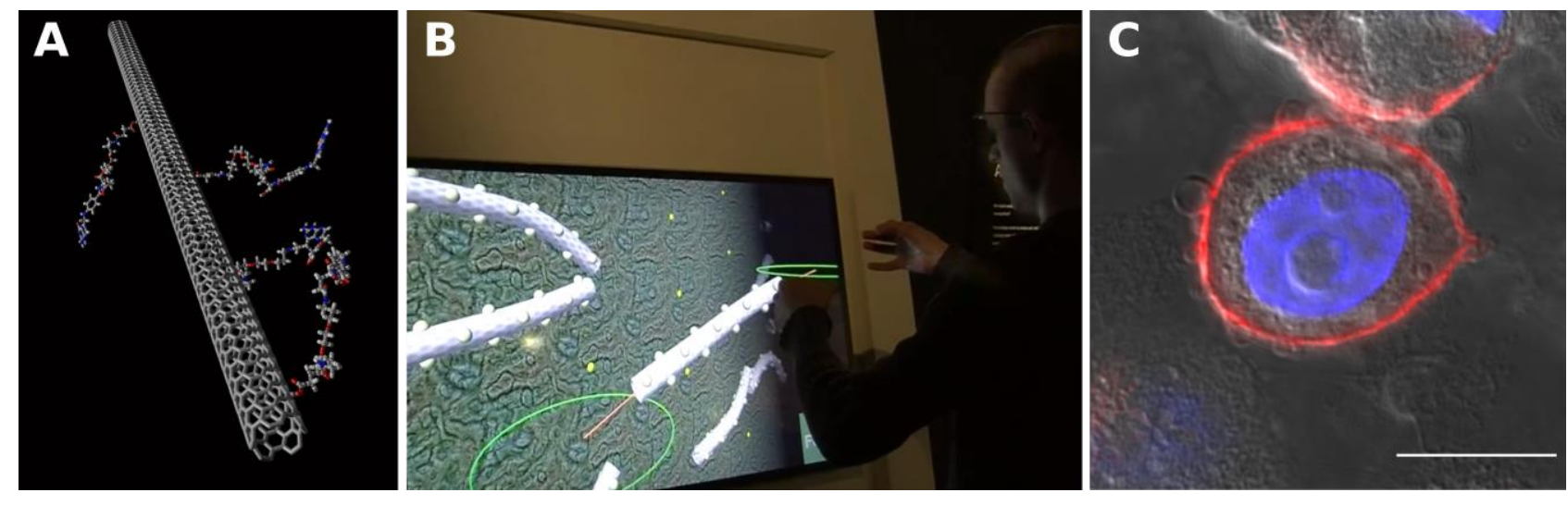

Figure 1 An immersive and interactive visualization environment for granting access to a simulated nanoworld. In this example, the virtual environment communicates principles behind targeted drugdelivery. A) A functionalized nanotube modelled in the simulation. B) A user interacts with functionalized nanotubes (visualized in grey with attached molecules in yellow) in the vicinity of a cancer cell membrane that expresses specific receptors (also in yellow). C) A microscopic image integrated in the system showing functionalized nanotubes (red) bound to the cancer cell membrane (cell nucleus in blue), where the bar represents $10 \mu \mathrm{m}$ (image from [32]). 

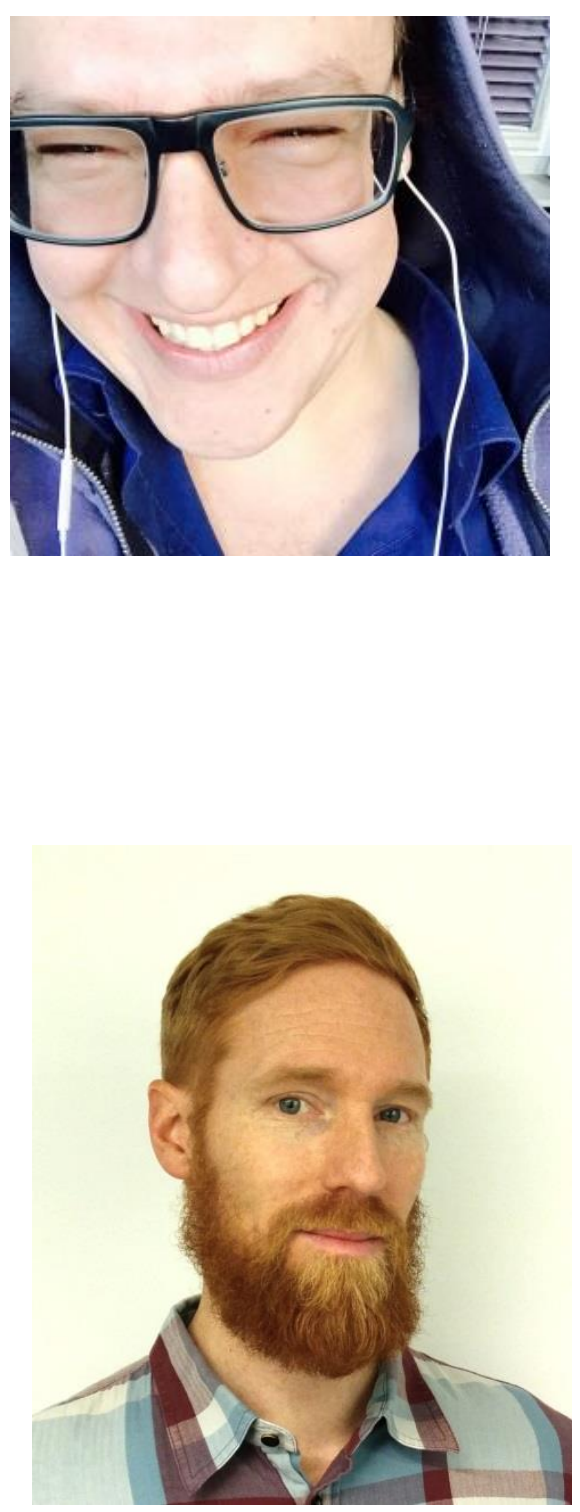

Konrad Schönborn has a Ph.D. in biochemistry education from the University of KwaZulu-Natal, South Africa. He is a senior lecturer in visual learning and communication at Linköping University, and coordinator of the Swedish national graduate school in science, mathematics, and technology education (FontD). His research explores how learners' interact with multiple external representations in the visualization and construction of conceptual understanding about molecular, (bio)chemical and physical phenomena. One of his current foci is on investigating the learning, teaching and communication of nanoscience and nanotechnology in public and classroom contexts.

Gunnar Höst received a Ph.D. in molecular biotechnology in 2007 from Linköping University. He is a senior lecturer in visual learning and communication at Linköping University. His current research investigates conceptual learning using virtual and tangible models, communication and meaning-making of biological and molecular phenomena, and he also teaches advanced level biochemistry courses.

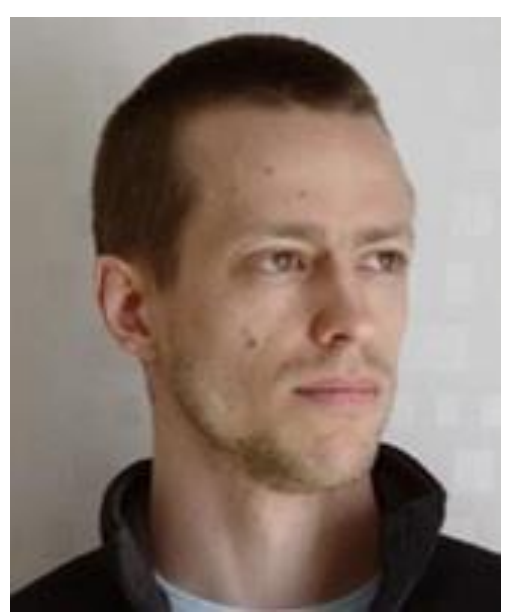

Karljohan Lundin Palmerius is a senior lecturer in immersive visualization at Linköping University. He conducts research and teaches in computer science and virtual reality technologies. He received his Ph.D. in 2007 from Linköping University specialising in scientific visualization with multimodal interfaces. His main interest and most significant part of his publications to date relate to haptic interfaces. He is the coordinator and main developer of an open source package for multimodal scientific visualization, and another for building virtual reality applications. An aspect of his recent work has included constructing virtual reality architectures for the exposure, learning and teaching of core nano-related concepts. 